\title{
Post Operative Discitis- A Review of 10 Patients in A Tertiary Care Neurosurgical Unit.
}

\author{
Dr. Bhavanam Hanuma Srinivas ${ }^{1}$, Dr. Duttaluru Seshadri Sekhar ${ }^{2}$, \\ Dr. Gaddala Penchalayya ${ }^{3}$, Dr. Kesanakurthi Satyanarayana Murthy ${ }^{4}$. \\ ${ }^{1,2}$ Assistant Professors, ${ }^{3}$ Post Graduate, ${ }^{4}$ Professor. \\ 1,2,3,4 Department Of Neurosurgery, Guntur Medical College, Guntur, Andhra Pradesh
}

\begin{abstract}
:
Background: Postoperative discitis is an uncommon complication of spine surgery with estimated incidence rate usually less than $1 \%$. It is defined as primary infection of nucleus pulposus with secondary involvement of cartilaginous end plates and adjacent vertebral bodies following lumbar disc surgeries ${ }^{2}$. Early diagnosis based on clinical, laboratory, imageological findings and identification of causative agent and appropriate management of discitis is essential to reduce morbidity. The aim of this study was to identify the associated risk factors, most common level of discitis and outcome of conservative management in cases of post operative discitis of single level discectomy.

Materials \& Methods:The study was carried out retrospectively over a period of 6 months from Jan 2014 to Dec 2015. Total 192 cases were operated electively for single level lumbar spine disorders. Post op discitis was established by clinical, laboratory \& radiological findings.

Results: During the study period 192 single level discectomies were performed. Out of 192 patients 10 patients(5.2\%) were suffered from discitis. The mean age of patients of postop discitis was 44 years with 4 women and 6 men. Among these 10 patients 3 were diabetic under good glycemic control. Most common clinical presentation is moderate to severe low backache. Out of 10 patients 7 patients corresponds to L4/L5 level. After 6 weeks of antibiotic therapy (3 weeks i.v. +3 weeks oral) with complete bed rest all patients were improved symptomatically. After 6 months of follow up all patients were able to carry on their daily activities.

Conclusions: Post operative discitis is an uncommon but serious complication of disc surgeries. Early diagnosis and appropriate antibiotic therapy along with immobilisation is essential in the management.
\end{abstract}

Keywords: C Reactive protein, Magnetic resonance imaging(MRI), Post op discitis.

\section{Introduction}

Post operative discitis first case reported in 1953 by Turnbull ${ }^{3}$. It is defined as inflammation of end plates of vertebra and infection of inter vetebral disc space after discectomy. The infection can spread either from patient skin due to aseptic precaution or hematogenous spread from Gastrointestinal tract / urinary tract ${ }^{4}$. Sometimes the source remain unknown. Post operative discitis usually noticed from 4 days to 1 month after spine surgery. Usually these patients presented with severe low backache with/without radiculopathy. Raised ESR and $C$ reactive protein will be contributory for diagnosis but MRI is the investigation of choice.

\section{Material \& Methods}

The study was carried out retrospectively over a period of 1 year. Total 192 patients were included in this study who underwent single level lumbar disc surgery. Among these 192 patients 10 patients were diagnosed with postoperative discitis. We reviewed the medical records and management of this particular post operative discitis patients. Descriptive analysis was provided in table 1

Patient characteristics: There were 6 males and 4 females with an average age of 44 years. Out of 10 patients who suffered from discitis 7 belongs to L4/L5 level. The most common symptom was low backache which was worsened with movements. 2 patients suffered from fever and 3 patients had associated radiculopathy along with backache.

Risk factors: Out of 10 patients 2 were chronic smokers, 3had obesity,3 patients had diabetes mellitus with good glycemic control.

Laboratory analysis: All 10 patients were investigated for ESR, C Reactive protein and Total leucocyte count .out of 10 patients 2 had raised leucocyte levels, 6 had raised ESR(>25 mm/hr). Interestingly all patients had raised $\mathrm{C}$ reactive protein levels $(>12 \mathrm{ng} / \mathrm{l})$ and one patient had blood culture positive for staphylococci. 
Imageology: $\mathrm{X}$ rays done for all cases who suffered from discitis to see the reduction in disc space and end plate changes.MRI was the investigation of choice for detection of changes in postop discitis.T1, T2 Weighted images will be helpful to see the contour irregularities of vertebral end paltes at the level of operated disc, changes of edematous type in adjacent vertebral bodies. Contrast will be helpful to see the extension of discitis into posterior para vertebral muscles, anterior epidural \& psoas muscles. Follow up MRI done after 6 months.

Treatment: All patients were readmitted after initiation of symptoms and advised complete bed rest for 3 months. Total 6 weeks of antibiotic therapy ( 3 weeks iv +3 weeks oral) along with limited analgesics given for all patients.

Antibiotic protocol: i.v Linezolid/Vancomycin+amikacin+ornidazole

Oral Linezolid+ofloxacin+ornidazole.

After 2 weeks of initiatin of therapy showing decresed levels ESR and c reactive protein. At the end of 6 weeks antibiotic therapy, patients had symptomatic relief. Psychological support given to all patients. At the end of 6 months follow up all patients were completely symptom free and able to do their daily activites.

\section{Discussion}

Post operative discitis is an uncommon entity after spine surgery which can be either septic or aseptic cause $^{5,6}$. The incidence of discitis varies from 0.21 to $3.6 \%$ as per existing literature but in the present study it was little higher side $(5.2 \%)^{7}$. In present study most of the discitis patients corresponds to 32 to 68 yrs age group and majority are male preponderance(1.5:1). The period between surgery and onset of symptoms was 4 days to 1 month which was as similar as existing literature. Clinical features in most of the patients in present study was similar to existing literature ${ }^{8,9}$. In present study discitis patients presented with severe to moderate intensity low back ache with or without radiculopathy, muscle spasm \& fever. 3 of our patients were diabetic, but Piotrowaski et al found that $26 \%$ of patients with post operative discitis had diabetes.

Early diagnosis of discitis usually done on the basis of clinical,laboratory and imageological findings.Elevated levels of ESR \& C- reactive protein are suggestive of discitis but not confirmatory ${ }^{10,11}$. Usually CRP elevated until 10 th post operative day, so any patient postoperatively unexpected rise in CRP beyond 2 weeks should suspect postoperative discitis. Some studies suggest CRP is a most sensitive indicator for diagnosis of post operative discitis ${ }^{12}$. In the present study $20 \%$ patients had raised TLC levels, $60 \%$ had raised ESR and $100 \%$ had raised CRP levels. Present study also suggesting raised CRP may be a sensitive indicator for diagnosing postoperative discitis.

MRI is the best investigation of choice for accurate diagnosis of postoperative discitis which shows florid inflammatory signs with granulation tissue ${ }^{13}$. Contrast will be helpful to see the extent of discitis. Some studies suggesting percutaneous endoscopic/CT guided biopsy and culture will be helpful in diagnosis and management ${ }^{14}$. In present study all patients were underwent MRI for diagnosis and no patient had biopsy. In literature most of the studies showed staphylococcus aureus was the most common pathogen identified in the cultures $^{15}$. In present study antibiotic treatment was started in all cases along with bed rest and analgesics and showed reduction in CRP levels along with dramatic relief of symptoms at the end of 6 weeks and returned to daily activities at the end of 6 months follow up. In literature no standardized management protocol for post operative discitis ${ }^{16}$. We suggesting complete immobolisation and 6 weeks of antibiotic therapy is essential in the management of post operative discitis. In literature some authors suggesting surgical debridement and instrumentation may be needed in few cases where conservative management failed ${ }^{17,18}$. In present study we did not encounter that problem and all were improved clinically with conservative management only and returned to their daily activities at the end of 6 months follow up.

\section{Conclusion}

Post operative discitis is an uncommon but serious complication after disc surgery. It should be suspected on clinical basis along with raised CRP levels.MRI is the investigation of choice for diagnosis of post operative discitis. Absolute bed rest and appropriate antibiotic therapy(atleast 6 weeks) is the main stay in the management of post operative discitis. The prognosis of post op discitis is good with conservative management in most of the patients without any complications.

Table 1: Descriptive analysis of study participants $(\mathrm{n}=10)$

\begin{tabular}{|ll|l|}
\hline Patients & Number(Frequency) \\
\hline Age & $\begin{array}{l}\text { Median } \\
\text { Range }\end{array}$ & 44 \\
& Male & $6(60 \%)$ \\
\hline
\end{tabular}




\begin{tabular}{|c|c|}
\hline Female & $4(40 \%)$ \\
\hline $\begin{array}{l}\text { Level of initial surgery } \\
\text { L3-L4 } \\
\text { L4-L5 } \\
\text { L5-S1 }\end{array}$ & $\begin{array}{l}1(10 \%) \\
7(70 \%) \\
2(20 \%)\end{array}$ \\
\hline 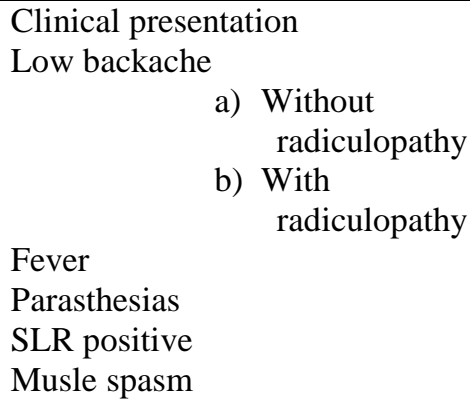 & $\begin{array}{l}10(100 \%) \\
7 \\
3 \\
2(20 \%) \\
1(10 \%) \\
6(60 \%) \\
6(60 \%)\end{array}$ \\
\hline $\begin{array}{l}\text { Risk factors } \\
\text { Smoking } \\
\text { Obesity } \\
\text { Diabetes }\end{array}$ & $\begin{array}{l}2(20 \%) \\
3(30 \%) \\
3(30 \%)\end{array}$ \\
\hline
\end{tabular}

\section{References}

[1]. Ford LT, Key JA (1955) Postoperative infection of intervertebral disc space. South Med J 48(12):1295-1303.

[2]. Hamdan TA. Postoperative disc space infection after discectomy: a report on thirty-five patients. Int Orthop. 2012 Feb;36(2):44550 .

[3]. Turnbull F. Postoperative inflammatory disease of lumbar discs. J Neurosurg. 1953 Sep;10(5):469-73.

[4]. Adam D, Papacocea T, Hornea I, Croitoru R. Postoperative spondylodiscitis. A review of 24 consecutive patients. Chirurgia (Bucur). 2014 Jan-Feb;109(1):90-4.

[5]. Santhanam R, Lakshmi K. A Retrospective Analysis of the Management of Postoperative Discitis: A Single Institutional Experience. Asian Spine J. 2015;Aug;9(4):559-64.

[6]. Tronnier V, Schneider R, Kunz U, Albert F, Oldenkott P. Postoperative spondylodiscitis: results of a prospective study about the aetiology of spondylodiscitis after operation for lumbar disc herniation. Acta Neurochir (Wien) 1992;117:149-152.

[7]. El-Gindi S, Aref S, Salama M et al. (1976) Infection of intervertebral discs after operation. J Bone Joint Surg Br 58:114-116.

[8]. Jimenez-Mejias ME, de Dios Colmenero J, Sanchez-Lora FJ, et al. Postoperative spondylodiskitis: etiology, clinical findings, prognosis, and comparison with nonoperative pyogenic spondylodiskitis. Clin Infect Dis. 1999;29:339-345.

[9]. Rohde V, Meyer B, Schaller C, Hassler WE. Spondylodiscitis after lumbar discectomy: incidence and a proposal for prophylaxis. Spine (Phila Pa 1976) 1998;23:615-620.

[10]. Boden SD, Davis DO, Dina TS, Sunner JL, Wiesel SW. Postoperative diskitis: distinguishing early MR imaging findings from normal postoperative disk space changes.Radiology. 1992;184:765-771.

[11]. Frank AM, Trappe AE. The role of magnetic resonance imaging (MRI) in the diagnosis of spondylodiscitis. Neurosurg Rev. 1990;13:279-283.

[12]. . Perronne C, Saba J, Behloul Z, et al. Pyogenic and tuberculous spondylodiskitis (vertebral osteomyelitis) in 80 adult patients. Clin Infect Dis. 1994;19:746-750.

[13]. Van Goethem JW, Parizel PM, van den Hauwe L, Van de Kelft E, Verlooy J, De Schepper AM. The value of MRI in the diagnosis of postoperative spondylodiscitis.Neuroradiology. 2000;42:580-585.

[14]. Yang SC, Fu TS, Chen LH, Chen WJ, Tu YK. Identifying pathogens of spondylodiscitis: percutaneous endoscopy or CT-guided biopsy. Clin Orthop Relat Res.2008;466:3086-3092.

[15]. Rawlings CE, 3rd, Wilkins RH, Gallis HA, Goldner JL, Francis R. Postoperative intervertebral disc space infection. Neurosurgery. 1983;13:371-376.

[16]. Silber JS, Anderson DG, Vaccaro AR, Anderson PA, McCormick P. Management of postprocedural discitis. Spine J. 2002;2:279287.

[17]. Rayes M, Colen CB, Bahgat DA, et al. Safety of instrumentation in patients with spinal infection. J Neurosurg Spine. 2010;12:647659.

[18]. Lee MC, Wang MY, Fessler RG, Liauw J, Kim DH. Instrumentation in patients with spinal infection. Neurosurg Focus. 2004;17:E7.

Legends : Post operative MRI images A) showing L4/L5 disc space infection with end plate and adjoining vertebral body changes and epidural and para vertebral collection(Day 14). B) showing resolution of infection after 3 months. 
Post Operative Discitis- A Review Of 10 Patients In A Tertiary Care Neurosurgical Unit.
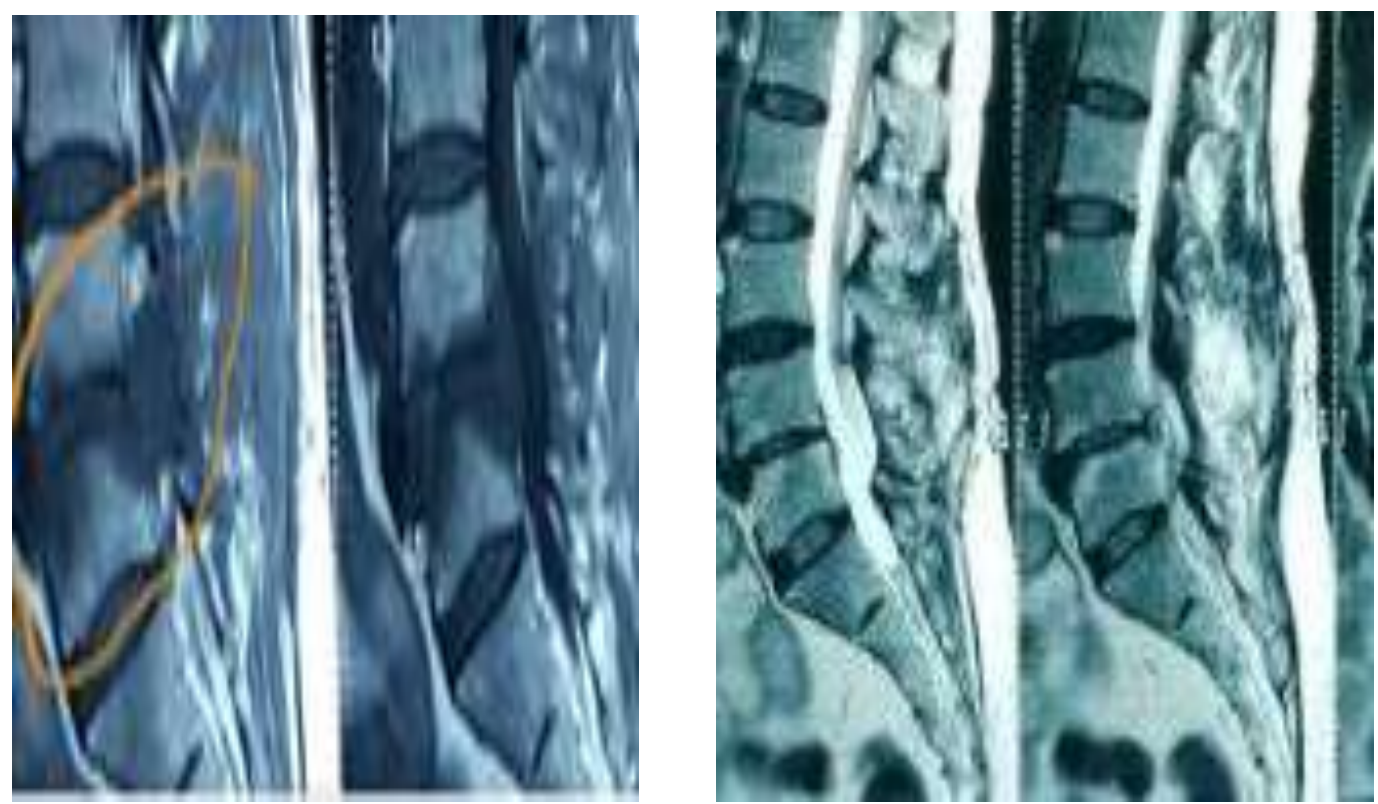